\title{
NT-3 facilitates hippocampal plasticity and learning and memory by regulating neurogenesis
}

\author{
Kazuhiro Shimazu, ${ }^{1}$ Mingrui Zhao, ${ }^{1}$ Kazuko Sakata, ${ }^{1}$ Schahram Akbarian, ${ }^{2,3}$ \\ Brian Bates, ${ }^{2,4}$ Rudolf Jaenisch, ${ }^{2}$ and Bai Lu' ${ }^{1,5}$ \\ ${ }^{1}$ Section on Neural Development and Plasticity, National Institute of Child Health and Human Development, National Institutes \\ of Health, Bethesda, Maryland 20892, USA; ${ }^{2}$ Whitehead Institute for Biomedical Research, Massachusetts Institute \\ of Technology, Cambridge, Massachusetts 02142, USA
}

\begin{abstract}
In the adult brain, the expression of NT-3 is largely confined to the hippocampal dentate gyrus (DG), an area exhibiting significant neurogenesis. Using a conditional mutant line in which the NT-3 gene is deleted in the brain, we investigated the role of NT-3 in adult neurogenesis, hippocampal plasticity, and memory. Bromodeoxyuridine (BrdU)-labeling experiments demonstrated that differentiation, rather than proliferation, of the neuronal precursor cells (NPCs) was significantly impaired in DG lacking NT-3. Triple labeling for BrdU, the neuronal marker NeuN, and the glial marker GFAP indicated that NT-3 affects the number of newly differentiated neurons, but not glia, in DG. Field recordings revealed a selective impairment in long-term potentiation (LTP) in the lateral, but not medial perforant path-granule neuron synapses. In parallel, the NT-3 mutant mice exhibited deficits in spatial memory tasks. In addition to identifying a novel role for NT-3 in adult NPC differentiation in vivo, our study provides a potential link between neurogenesis, dentate LTP, and spatial memory.
\end{abstract}

One of the two regions where adult neurogenesis occurs is at the dentate gyrus (DG) of the hippocampus (Gage 2000). The generation of new neurons in the adult dentate is a multistep process. Initially, stem cell-derived progenitor cells proliferate in the subgranular zone of the DG. These cells then migrate into the granule cell layer, where they differentiate into neurons and glial cells (Kempermann et al. 2004a). During the process, some of the differentiated and undifferentiated cells die. A subset of surviving new neurons, however, gradually develop functional neuronal properties, form new synapses, and integrate into the existing neural network (Song et al. 2002; van Praag et al. 2002). Defining diffusible factors that regulate this process constitutes one of the most active areas in neural stem cell biology (Gage 2000; Gould and Gross 2002).

Neurotrophin-3 (NT-3, also known as Ntf3) may serve as an excellent candidate as a diffusible factor that regulates dentate neurogenesis. The expression of the NT-3 gene in the adult brain is highly confined to the dentate gyrus (Maisonpierre et al. 1990; Friedman et al. 1991; Lauterborn et al. 1994). Elevated neuronal activity, either by LTP-inducing stimuli or ischemia, enhances the expression of NT-3 mRNA in the dentate (Lindvall et al. 1992; Bramham et al. 1996). Cell culture experiments showed that NT-3 antagonizes the proliferative effects of basic fibroblast growth factor (bFGF) on progenitor cells, and enhances the differentiation of newborn neurons (Ghosh and Greenberg 1995; Vicario-Abejon et al. 1995; Barnabe-Heider and Miller 2003). In addition, dietary restriction enhanced the expression of NT-3 in dentate gyrus, paralleling the increase in the number of newborn neurons (Lee et al. 2000). However, direct evidence for the role of

Present addresses: ${ }^{3}$ Brudnick Neuropsychiatric Research Institute, Department of Psychiatry, University of Massachusetts Medical School, Worcester, MA 01613, USA; ${ }^{4}$ Wyeth Research, Applied Genomics, Cambridge, MA 02140, USA. ${ }^{5}$ Corresponding author.

E-mail bailu@mail.nih.gov; fax (301) 496-1777.

Article published online before print. Article and publication date are at http:// www.learnmem.org/cgi/doi/10.1101/lm.76006. endogenous NT-3 in the proliferation, survival or differentiation of hippocampal progenitor cells in vivo is lacking.

The functional significance of adult neurogenesis remains one of the key unsolved issues in neuroscience (Fuchs and Gould 2000; Kempermann et al. 2004b). Although there may be a correlation between neurogenesis and memory, the relationship remains controversial (Gould et al. 1999b; Lu and Chang 2005). Activities known to enhance learning and memory, such as exercise or living in an enriched environment, promotes neurogenesis in the adult hippocampus (Kempermann et al. 1997; Nilsson et al. 1999; van Praag et al. 1999a,b; Cotman and Berchtold 2002). Learning itself has also been shown to enhance the survival of newly generated neurons in the dentate (Gould et al. 1999a). The most direct evidence so far was demonstrated in an experiment in which inhibition of neurogenesis using a mitotic inhibitor impaired hippocampal-dependent, but not hippocampal-independent memory (Shors et al. 2001). Inhibition of neurogenesis by radiation also impaired hippocampus-dependent, place-recognition task, and spatial memory retention, but not object-recognition task (Madsen et al. 2003; Rola et al. 2004). An attractive hypothesis is that at least some forms of hippocampusdependent memory are mediated by the generation of new neurons (Gould et al. 1999b; Kempermann 2002). How does this model reconcile the conventional belief that hippocampal LTP is a cellular model for hippocampus-dependent learning and memory? It is possible that newly generated neurons could contribute to the formation of new synapses, leading to alterations of LTP in the dendritic network of the dentate granule neurons. Indeed, running-enhanced neurogenesis is accompanied by a selective increase in dentate LTP (van Praag et al. 1999a). Newly generated granule neurons exhibit a lower threshold for LTP induction, but the magnitude of LTP is smaller when stronger stimulation is used (Schmidt-Hieber et al. 2004). The causal relationship between neurogenesis and LTP was implied in one study showing that inhibition of NPC proliferation drastically reduced LTP in the medial perforant path-dentate synapses (Snyder et al. 2001). It is unclear, however, whether inhibition of neurogenesis 
A

C

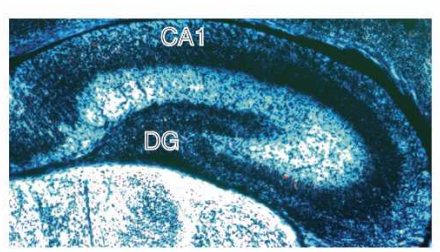

B

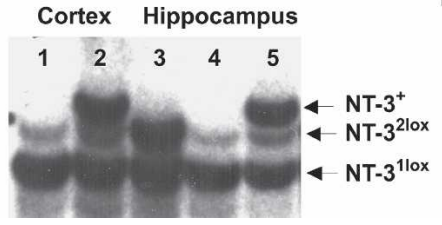

Figure 1. Cre-mediated recombination and ablation of the NT-3 gene in adult hippocampus. (A) Nestin-Cre mediated recombination in adult hippocampus (2-mo old). Coronal section from P2.5 animal [Nes-Cre/ ${ }^{+}$(male) X floxedROSA-26 ${ }^{\text {ref/+ }}$ (female)] stained by X-gal (dark blue) to detect cre-mediated recombination at the ROSA-26 locus and counterstained with Neutral red. Note the widespread and complete or nearcomplete recombination in hippocampus and cerebral cortex. (B) Southern blot showing Cre-mediated recombination in the hippocampus and cortex of adult mutant mice. DNA samples were prepared from brain

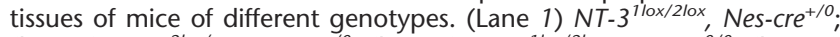

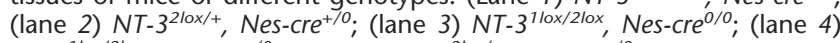

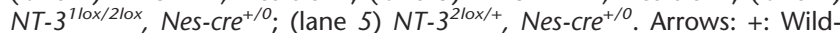

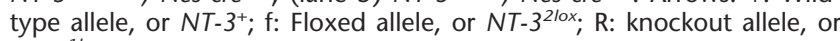
$N T-3^{1 l o x}$. (C) Northern blot analysis of mRNAs isolated from adult hippocampi of different genotypes. (Lane 1) NT-3 $3^{+/+}$, Nes-cre ${ }^{0 / 0}$; (lane 2) NT-

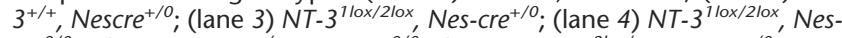

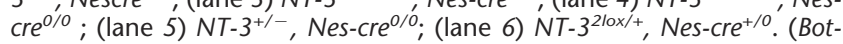
tom) rRNA loading control is shown below. Arrows point to the positions of $18 \mathrm{~S}$ and $28 \mathrm{~S}$ rRNAs.

could alter synaptic plasticity in the existing synaptic network, and if so, whether such alterations have behavioral consequences.

In the present study, the role of neurogenesis in hippocampal LTP and learning and memory was examined using a line of NT-3 conditional knockout mice, in which the NT-3 gene is selectively deleted in the brain throughout development. We tested whether NT-3 is involved in the proliferation or differentiation of progenitor cells in the dentate. We further investigated the role of neurogenesis in synaptic plasticity of specific synaptic pathways of dentate neurons and the underlying mechanisms. Finally, we examined the behavior deficits of the mutant mice. Our results suggest that NT-3 specifically regulates the differentiation, but not the proliferation of neuronal precursor cells in the dentate. Such regulation appears to be important for LTP in the lateral, but not medial perforant path-dentate synapses. These results may help us to understand how neurogenesis could contribute to long-term synaptic plasticity and memory.

\section{Results}

An NT-3 conditional mutant mouse, created using the cre/loxP system as previously described (Bates et al. 1999, 2002; Akbarian et al. 2001), was used. To ensure that Nes-Cre is expressed in the hippocampus, we crossed Nes-Cre transgenic mice with a Rosa26 reporter line that expresses $\beta$-galactosidase upon Cre-mediated removal of a stop codon (Soriano 1999). Strong expression was detected in the granule cell layer of the dentate gyrus and CA1CA3 regions of the hippocampus (Fig. 1A). Southern blot was performed using cortical and hippocampal tissues from various genotypes. We generated mice with different genotypes by mat- ing as previously described (Bates et al. 1999). We used the following nomenclature for the NT-3 alleles: Recombined: NT-3 $3^{1 l o x}$; Floxed: NT- $3^{\text {2lox }}$; Wild-type: NT $-3^{+}$(Bates et al. 1999). Thus, the genotype of conditional mutant is NT-3 $3^{1 \text { lox/2lox }}, \mathrm{Nes}-\mathrm{cre}^{+/ O}$. We used two types of mice as controls, i.e., $\mathrm{NT}-3^{+/+}, \mathrm{Nes}-\mathrm{Cr} e^{O / O}$, which is the wild-type and NT- $3^{2 l o x / 2 l o x}, N e s-\mathrm{Cre}^{O / O}$, which is the floxed animals. In the hippocampus, the homologous recombination was more than $80 \%$ completed in the mutant mice (Fig. 1B). Moreover, Northern blot revealed that NT-3 transcripts in the hippocampus from the NT-3 $3^{1 l o x / 2 l o x}, \mathrm{Nes}-\mathrm{Cr} e^{O / O}$ mice were essentially undetectable (Fig. 1C). NT-3 ELISA was used to measure the levels of NT-3 protein in adult hippocampus. We detected $5.35 \pm 0.28 \mathrm{pg} / 20 \mu \mathrm{g}$, and $15.50 \pm 1.17 \mathrm{pg} / 100 \mu \mathrm{g}$ NT-3 protein from the wild-type tissues, but none from the mutant tissues.

\section{Proliferation and survival of BrdU-positive cells in dentate gyrus}

Brains from our conditional mutant mice appeared normal (data not shown) except for a defect in cerebellar foliation, which is consistent with previous reports (Bates et al. 1999, 2002; Akbarian et al. 2001). Examination of hippocampal sections did not reveal any gross morphological abnormality (Fig. 2A). Since the endogenous NT-3 gene expression in adult was relatively confined to the dentate gyrus of the hippocampus (Maisonpierre et al. 1990; Lauterborn et al. 1994), we examined cytoarchitectural organization of this region in some detail. The volumes of the granule cell layer (GCL), hilus, the whole dentate gyrus (DG), or
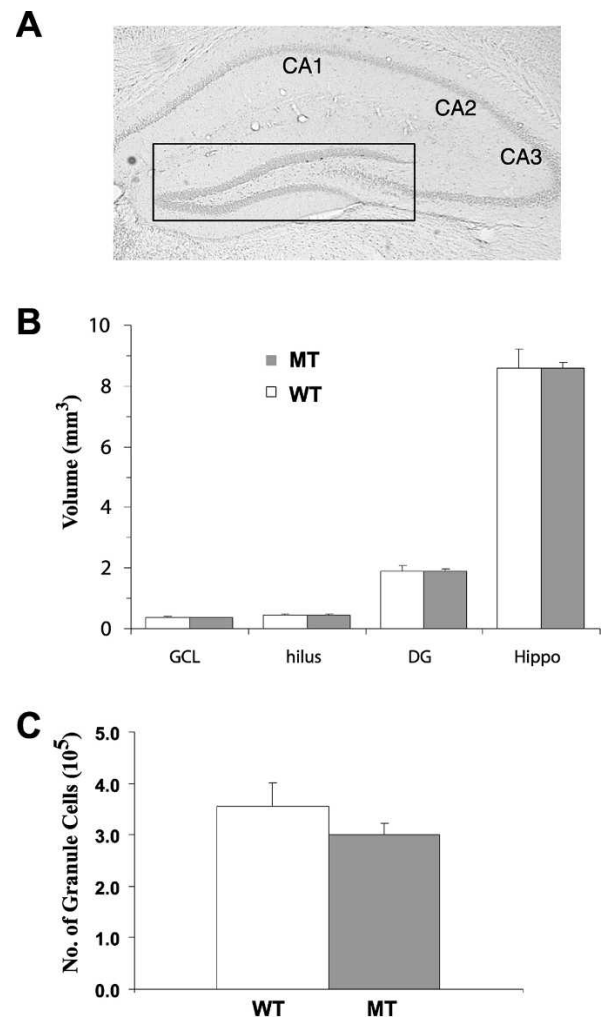

Figure 2. Normal morphology of adult hippocampus in NT-3 mutant mice. $(A)$ Low power $(4 \times)$ images of hippocampus from an NT-3 mutant mouse. H\&E staining reveals no abnormality of morphology of the hippocampus. (B) Quantitative measurement of the volumes of the subregions of hippocampus. The volumes of granule cell layer (GCL), the hilar region, the whole dentate gyrus (DG), and the whole hippocampus were measured. $n=6$ pairs of male mice; 2 -mo old. (C) Summary of cell counts. Total number of granule cells in DG is presented. $n=5$ pairs of 2-mo-old male mice. 
the whole hippocampal region (Hippo) in the mutant mice were almost identical to that of wild-type control (Fig. 2B). For cell counting, hippocampal sections were stained by the $\mathrm{H} \& \mathrm{E}$ method. Stereological analyses showed that there was no statistical difference in the number of granule neurons per dentate gyrus between wild-type and mutant mice (Fig. 2C). Thus, inactivation of the NT-3 gene does not result in obvious anatomical changes in the adult hippocampus.

Since NT-3 has been implicated in neurogenesis (Ghosh and Greenberg 1995; Vicario-Abejon et al. 1995), we asked whether deletion of the NT-3 gene could affect the proliferation or survival of neuronal precursor cells (NPCs) in adult dentate. To examine NPC proliferation, we pulse labeled the proliferating NPCs by injecting intraperitoneally bromodeoxyuridine (BrdU) $3 \mathrm{~h}$ before the brains were processed for BrdU immunohistochemistry. In this method, only a fraction of dividing cells were labeled, but the labeled cells would not have sufficient time to undergo more than one round of mitosis. BrdU(+) cells were found in both wild-type and mutant dentate, mostly beneath the granule cell layer with a few also in the hilus (Fig. 3A). There was no difference in the number of proliferating cells between wild-type and mutant mice (Fig. 3B). To examine the survival of the BrdUlabeled NPCs, we injected BrdU twice daily for $10 \mathrm{~d}$ so that a large proportion of dividing NPCs were labeled. In the remaining $2 \mathrm{wk}$ after the last BrdU injection, many NPCs underwent apoptosis. The surviving NPCs were detected by BrdU immunohistochemistry. We found that there was a small decrease in the number of $\mathrm{BrdU}(+)$ cells in the granule cell layer of the mutant mice, albeit barely significant compared with the wild-type mice (Fig. 3C) $(P=0.08, t$-test). No difference was detected in the hilus area. Taken together, these results suggest that NT-3 may regulate the survival, but not the proliferation, of NPCs in the dentate.

To determine whether NT-3 differentially affects the differentiation of the surviving NPCs into neurons and glia, we performed triple staining using the same sections derived from the
A

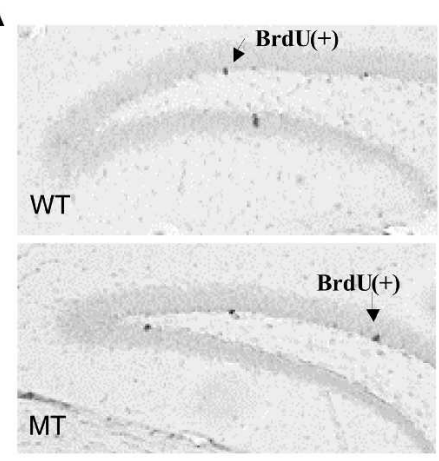

B

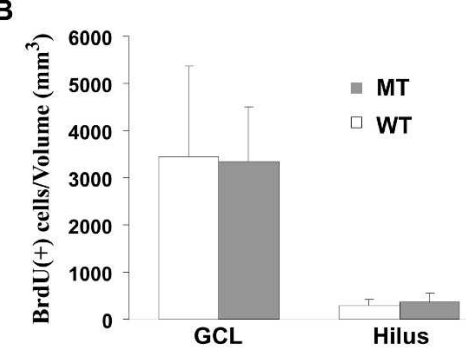

C

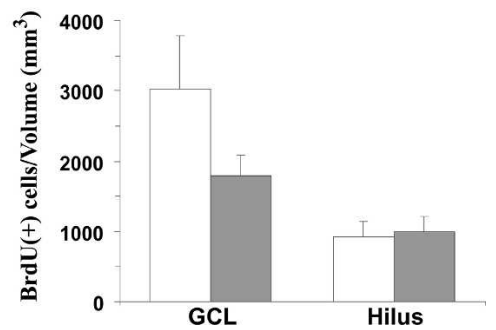

Figure 3. Effects of NT-3 deletion on proliferation and survival of NPC. (A) Medium-power $(20 \times)$ images of BrdU-labeled cells in the wild-type (top) and mutant (bottom) dentate gyrus. The sections were processed for BrdU immunohistochemistry followed by Nissl counter stain. (B) Effect on proliferation of NPCs. Three hours after BrdU was injected intraperitoneally, the brains of the injected animals were fixed and processed for BrdU histochemistry. The number of BrdU (+) cells in the hilus and granule cell layer $(\mathrm{GCL})$ were counted using sterological techniques. $n=3$ pairs of male mice; 4-mo old. (C) Effect on survival of NPCs. BrdU was injected twice daily for $10 \mathrm{~d}$, and BrdU immunohistochemistry was performed 2 wk after the last BrdU injection. Cells were counted the same way as B. $n=6$ pairs of male mice; 2 -mo old.
NPC survival study described above. BrdU was detected by a rat anti-BrdU antibody (green). A mouse anti-NeuN antibody (red) was used to label mature neurons, while a rabbit anti-GFAP an(purple) was used to label astrocytes. Fluorescence microscopy using three different wavelengths showed that BrdU, NeuN GFAP could be clearly detected in the same section (Fig. 4A) mer of $\mathrm{BrdU}(+)$ neurons was significantly reduced, while the num tant mice (Fig. 4B). Pie plots indicated that in the R/f, + mutant, increase in the number of neurons was accompanied by " ther" in Fig. 4C). These results suggest that in addition to NPC survival, NT-3 may affect maturation, or fate determination (to

\section{Synaptic transmission and plasticity}

NT-3 has been shown to both induce differentiation of hippo( hippocampal neurons (Vicario-Abejon et al. 1998, 2000). We ore examined whether the deficits in the survival and/o differentiation of dentate NPC in NT-3 mutant mice would result impairments in LTP. Two major sets of excitatory synapses on (LPP) and the other by medial (MP). By carefully positioning the stimulating synapses separately (Fig. 5A). Application of tetanic stimulation $(4 \times 0.5 \mathrm{sec}, 50 \mathrm{~Hz}, 30$-sec interval) to MPP induced a robust LTP in both wild-type and mutant MPP synapses, with very similar LPP synapses in mutant mice exhibit a severe deficit, as compared with that seen in wild-type mice (Fig. 5B, middle). The magnitude of LTP measured $60 \mathrm{~min}$ after tetanus $(4 \times 0.5 \mathrm{sec}, 50$ $\mathrm{Hz}, 30$-sec interval) was $156.3 \pm 9.6 \%$ in wild-type mice, but $121.2 \pm 9.1 \%$ in $\mathrm{R} / \mathrm{f},+$ mice, respectively $(P<0.001, t$-test $)$. As a control, we also recorded LTP at the Schaffer collateral-CA1 synapses. Tetanic stimulation $(2 \times 1 \mathrm{sec}, 100 \mathrm{~Hz}, 20$-sec interval $)$ induced identical LTP in wild-type and mutant mice (Fig. 5B, top). Thus, deletion of NT-3 gene selectively impairs LPP-granule cell synapses in hippocampal dentate.

LTP at dentate synapses is facilitated by inhibiting $\mathrm{GABA}_{\mathrm{A}}$ receptormediated transmission (Hanse and Gustafsson 1992). Since NT-3 has been shown to attenuate GABAergic transmission in relatively mature neurons (Kim et al. 1994), one potential mechanism by which NT-3 enhances LTP is to suppress GABAergic inputs to the granule neurons. If the LPP-LTP deficit seen in NT-3 mutant mice was due to an increased GABAergic inhibition, one would expect no difference between wild-type and mutant mice when GABAergic transmission is completely blocked. To test this possibility, we recorded LPP-LTP in the presence of $\mathrm{GABA}_{\mathrm{A}}$ antagonist bicuculline $(10 \mu \mathrm{M})$. Unlike MPP synapses recorded in the submerged chamber (Snyder et al. 2005), application of bicuculline did not seem to dramatically in- 
A
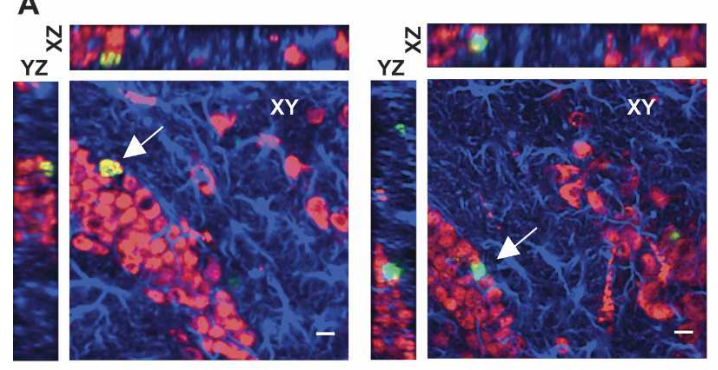

C

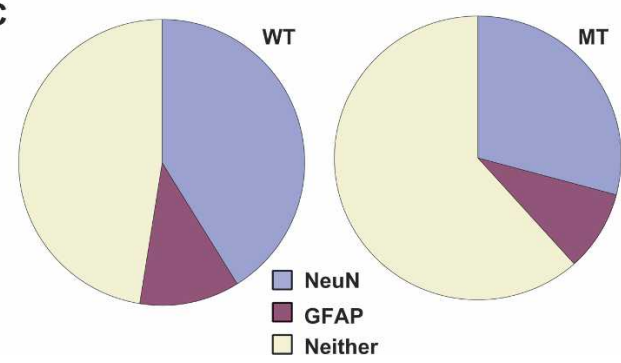

B

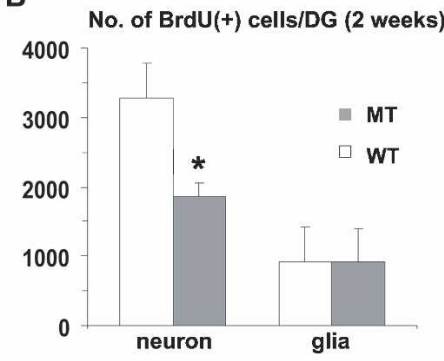

ratio is usually greater than one. PPFs at interpulse intervals of 10,20 , and 50 msec were markedly reduced in the $\mathrm{R} / \mathrm{f}$, + mice as compared with wild-type mice (Fig. 6B), suggesting an alteration in presynaptic properties. This result is consistent with previous reports, which used $\mathrm{NT}^{-3^{+/-}}$mice (Kokaia et al. 1998; Asztely et al. 2000). Finally, to determine whether NT-3 gene deletion also affects the number of synaptic vesicles in the reserved and readily releasable pools, we measured synaptic responses to a prolonged, low-frequency stimulation (LFS) and a brief, high-frequency stimulation (HFS), respectively (Cabin et al. 2002). As shown in Figure 6, D and E, no differences were observed between wild-type and mutant mice in either response. These results suggest that the deletion of the NT-3 gene does not alter synaptic vesicle distribution.

Figure 4. Effect of NT-3 deletion on NPC-derived neurons and glia. Wild-type and mutant mice were injected with BrdU twice/day for $10 \mathrm{~d}$. Two weeks later, the animals were processed for triple labeling for BrdU (green), NeuN (red), and GFAP (blue), using confocal microscopy. (A) Confocal images of BrdU-positive neurons (left) and astroglia (right). (B) Quantitative analysis of the number of NPC-derived neurons (left) and that of glia (right) in the dentate of control and mutant mice. $n=6$ pairs of male mice; 2 -mo old. $\left(^{*}\right)$ Significantly different between control and mutant mice, $P<0.01$, Student's $t$-test, two-tailed. (C) Relative distribution of cells derived from NPCs. $n=6$ pairs of male mice; 2-mo old.

crease the magnitude of LTP in LLP synapses recorded in the interface chamber (Fig. 5C). Surprisingly, the difference in LTP between the wild-type and mutant mice was much bigger when slices were treated with bicuculline, as compared with that without bucuculline (Fig. 5B,C). As an additional control, we recorded LTP in the floxed mice, which contains floxed NT-3, but not Cre-recombinase $\left(N T-3^{2 l o x / 2 l o x}, N e s-\mathrm{Cre}^{O / O}\right)$. The LTP in these mice were almost identical to that in wild-type mice (Fig. 5C). Given that NT-3 has also been shown to enhance GABAergic transmission, which in developing neurons is excitatory rather than inhibitory (Gao and van den Pol 1999), deletion of the NT-3 gene may reduce the excitatory effects of GABA, leading to impairments of LTP at the LPP synapses made by the NPC-derived cells.

We performed a series of experiments to investigate the potential mechanisms underlying the LTP deficit seen at LPP synapses. First, we examined the basal synaptic transmission. Field EPSPs were evoked by stimulating LPP with increasing stimulus intensity. The slope of EPSPs was plotted against stimulus intensity to establish input-output relationships. No difference was observed in the input-output curves in wild-type and mutant synapses (Fig. 6A), suggesting that the deletion of the NT-3 gene does not alter basal synaptic transmission. Next, we examined post-tetanic potentiation (PTP), a phenomenon thought to be due to enhanced presynaptic transmitter release (Zucker 1989). PTP was induced by tetanic stimulation in the presence of NMDA receptor antagonist APV. The magnitude of PTP at 1 min after tetanus, defined as a percentage increase of the average EPSP slope over baseline, was significantly reduced in slices from R/f, + mice $(129.1 \pm 6.0 \%)$, as compared with the ones from $+/+$ animals (148.1 $\pm 6.9 \%$, Fig. 6C). Since changes in PTP reflect presynaptic problems, we further examined paired-pulse facilitation (PPF), a form of plasticity that reflects changes in the probability of transmitter release (Zucker 1989). PPF was measured as the ratio of two consecutive EPSP slopes. At the LPP synapses, the den platform, which was kept at a constant location, using external visual cues. To test the learning capability, we measured escape latency (time to find the hidden platform), which became progressively shortened during a 7-d training period (twice daily) in wild-type mice (Fig. 7A). In marked contrast, the NT-3 mutant mice exhibited significantly longer latency times to find the hidden platform (Fig. 7A), indicating that they had a severe problem learning. Overall, the escape latency of NT-3 mutant mice improved much slower relative to wild-type mice during the $7 \mathrm{~d}$ of training.

At the end of the learning period, the platform was removed and the animals were given a 60 -sec probe trial to test their memory, which was measured by the percentage of time they spent in the platform quadrant (Fig. 7B). When the probe trial was administered $3 \mathrm{~d}$ after the end of training, wild-type mice spent more time in the correct quadrant (platform, 43\%) than all other quadrants. In contrast, NT-3 mutant mice spent only $9.1 \%$ of their time in the platform quadrant (Fig. 7B), indicating that their ability to remember the correct quadrant was severely compromised. Interestingly, the mutant mice also spent more time in the left quadrant (40\%). It is unclear whether this reflects a trend in which the mutant animals tend to stay in areas closer to the platform. The memory capacity can also be reflected by the number of times the animals crossed the platform area and the distance the animals traveled in the correct quadrant after the platform was removed. Figure $7 \mathrm{C}$ depicts examples of the swimming tracks by a wild-type and a mutant mouse. The wild-type mouse swam a significantly longer distance in the correct quadrant than the mutant mouse. Moreover, the wild-type mouse crossed the platform areas about six times in a minute, while the mutant crossed only once per minute.

Recently, NT-3 mutant mice generated by a different cre/ loxP system were shown to have defects in geniculocortical projections, leading to impairments in visual function (Ma et al. 
A

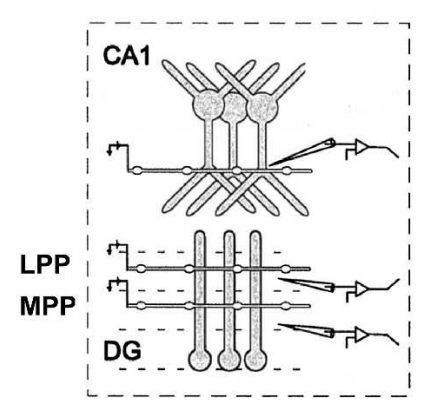

C

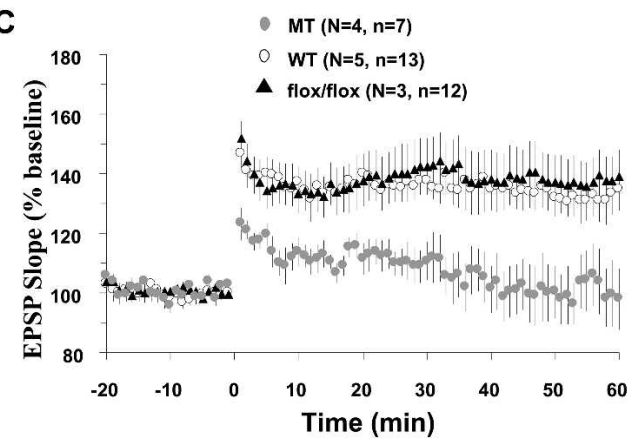

B

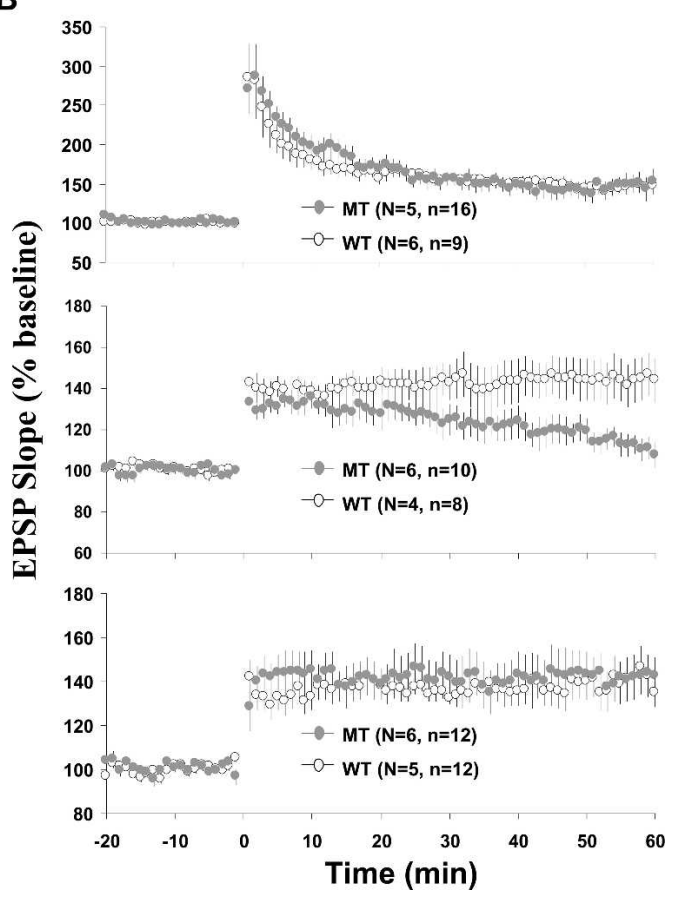

Figure 5. NT-3 regulates synaptic plasticity at a subset of hippocampal synapses. (A) Schematic showing the arrangement of stimulating and recording electrodes in CA1 (top) and DG (bottom). (B) LTP recordings in the CA1 region (top), the lateral perforant path (LPP) (middle), and the medial perforant path (MPP) (bottom). Tetanic stimulation was applied at time "0". Data from multiple slices $(n)$ were pooled and expressed as mean \pm SEM. (C) LTP deficit in LPP synapses in the presence of GABAa antagonist bicuculline $(10 \mu \mathrm{M})$. Mice with the NT-3 gene floxed $\left(N T\right.$ - $3^{2 / 0 x / 210 x}$, Nes-cre $e^{0 / 0}$, indicated as flox/flox) were studied as an additional control. Number of mice $(N)$ and slices $(n)$ are indicated in the figure. All mice used in electrophysiology and behavior experiments were between 1.5 and 2.5-mo old.

2002). Using the same visual cliff avoidance test, we found no such impairment in visual function in our mutant mice. Both wild-type and mutant mice spent most of their time on the covered (bench) side of the visual cliff box without crossing the cliff edge. The time spent on the open (suspended) side was $17.8 \pm 15.3 \%$ for NT-3 mutant and $27.7 \pm 12.8 \%$ for control mice ( $n=5$ pairs, $P>0.05$ ). These results suggest that our NT-3 mutant mice have relatively normal visual function. We also measured locomotor activity of the mice using a Digiscan activity monitor (a 16-inch square chamber equipped with two rows of $16 \times 16$ infrared sensors). These sensors were used to localize the animal's floor position on an $x-y$ plane, and automatically measure their horizontal and vertical movements. As shown in Figure $7 \mathrm{D}$, there was no statistical difference in any of the parameters measured between the wild-type and NT-3 mutant mice. Specifically, the mutant mice did not show any abnormality in total distance traveled, horizontal and vertical beam breaks, or time spent at the edge and center of the box. Thus, the cognitive deficits in NT-3 mutant mice are not likely to be accounted for by motor or visual deficits.

\section{Discussion}

NT-3 stimulates NPCs to differentiate into neurons in culture (Ghosh and Greenberg 1995; Vicario-Abejon et al. 1995). Deletion of the NT-3 receptor TrkC reduces the number of entorhinal afferents and the density of synaptic contacts in postnatal dentate (Martinez et al. 1998). However, since BrdU-labeling experiments were not performed, it is unclear whether the synaptic effects were due to facilitation of differentiation of NPC-derived neurons by NT-3. Our study demonstrates that the number of BrdU-labeled dentate cells in the NT-3 mutant mice are reduced.
More importantly, of the surviving BrdU cells in the NT-3 mutants, the number of NeuN-labeled neurons, but not GFAPlabeled glia, was significantly decreased, while the number of undifferentiated cells was increased. These results suggest that NT-3 is required to stimulate NPCs to differentiate into new neurons in the adult dentate in vivo.

An important, yet unresolved issue in the neural stem-cell field is the biological function of adult neurogenesis (Kempermann 2002; Kempermann et al. 2004b). It has long been speculated that adult neurogenesis is involved in learning and memory (Gould et al. 1999b), but how newly generated neurons contribute to learning and memory is not known. Inhibition of NPC proliferation in the adult dentate by either acute radiation (Madsen et al. 2003; Rola et al. 2004) or mitotic inhibition using MAM (Shors et al. 2001), leads to significant impairments in hippocampus-dependent memory. Interestingly, spatial learning, as assessed by the escape latency in the water-maze training, was not affected. Two caveats are noted. First, drugs such as MAM may interfere with protein synthesis or signaling mechanisms required for memory, or cause cytotoxic effects, and radiation may damage the stem-cell niche in the subgranular zone (Monje et al. 2002). Second, the mitotic inhibitor or radiation affects only the proliferation, but not differentiation, of the NPCs. In this study, we show that deletion of the NT-3 gene affects the differentiation, but not proliferation of NPCs. This apparently affects both learning and memory, as assessed by spatial navigation tests. Similarly, mice lacking methyl-CpG-binding protein 1 (MBD1) show deficits in NPC differentiation but not proliferation, as well as impairments in both learning and memory in water-maze tests (Zhao et al. 2003). These results raised the interesting possibility that the differentiation, but not proliferation of NPCs might somehow be involved in the spatial learning process. 
A

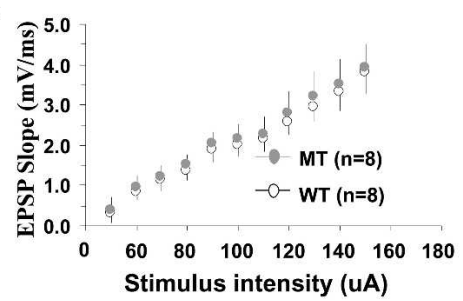

B
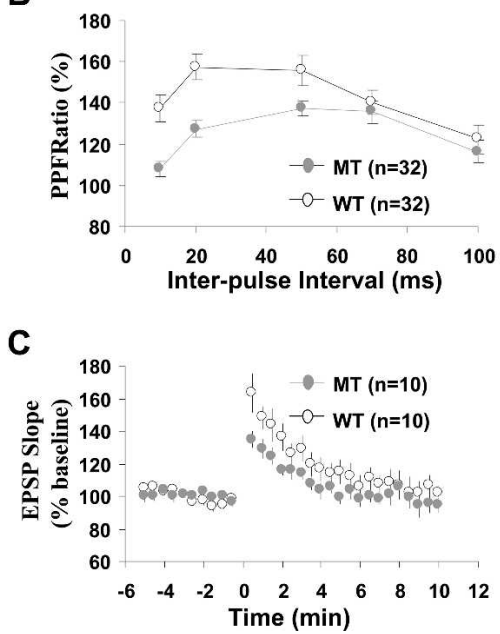

Figure 6. Impairments in presynaptic function of LPP-dentate synapses in NT-3 mutant mice. Numbers of slices recorded are indicated in the respective figures. (A) Input-output curves. No difference was observed between control and mutant mice. (B) Paired pulse facilitation (PPF). NT-3 mutant mice exhibit a substantial reduction in PPF at shorter interstimulus intervals. (C) Post-tetanic potentiation (PTP). PTP was induced by a tetanus $(100 \mathrm{~Hz}, 1 \mathrm{sec})$ in the presence of NMDA receptor blocker (Apv, $100 \mu \mathrm{M})$. There was a small, but significant decrease in PTP in the NT-3 mutant mice. (D) Synaptic fatigue. Synaptic responses to a brief, high-frequency stimulation (HFS, $100 \mathrm{~Hz}, 20$ pulses) were recorded. The slopes of all EPSPs were normalized to that of the 2nd EPSP. (E) Synaptic response to a prolonged, repetitive stimulation (LFS, 300 stimuli at $14 \mathrm{~Hz}, 280$ pulses).

The present study also provides a potential connection between adult neurogenesis and dentate LTP, and therefore a possible mechanism by which neurogenesis could contribute to hippocampus-dependent learning and memory. Since dentate LTP is believed to be critical for hippocampus-dependent memory (Richter-Levin et al. 1995; Abraham and Williams 2003), it is conceivable that adult neurogenesis participates in hippocampus-dependent learning and memory by regulating LTP at synapses in the dentate gyrus. Consistent with this idea, Wojtowicz and colleagues have shown that inhibition of neurogenesis by radiation selectively blocks ACSF-LTP in MPP, a form of LTP attributable to newborn young neurons (Snyder et al. 2001). The MBD1 mutant mice exhibit a parallel reduction in neurogenesis and an impairment in LTP at the MPP synapses (Zhao et al. 2003). We have now shown that deficits in NPC differentiation caused by a deletion of the NT-3 gene in the brain impairs LTP selectively at the LPP synapses. While we do not know whether the LPP-LTP is also impaired in the $\mathrm{MBD} 1^{-1-}$ mice, the selective impairment of LTP at the lateral, but not medial perforant path in the NT-3 mutant mice could be explained by a number of mechanisms. One possibility is that NT-3 may be required for dendritic growth and branching. Deletion of the NT-3 gene may therefore prevent newborn granule cells from extending their apical dendrites beyond MPP into LPP. Alternatively, NT-3 may selectively regulate the growth of LPP afferents. The deficits in PPF and PTP at the LPP synapses in the NT-3 mutant mice support this notion. Regardless of the mechanism, the normal LTP seen at the CA1 synapses in the NT-3 mutant mice suggest that NT-3 does not have a general effect on synapse formation in vivo. Consistent with this, LTP at the CA1 synapses was normal in another line of NT-3 conditional mutant mice that were generated by crossing NT-3 floxed mice with Cre transgenic mice, where the Cre gene was controlled by the synapsin I promoter to restrict expression to postnatal neurons (Ma et al. 1999). Finally, it should be pointed out that our results, albeit more specific than radiation or drug treatment, are still correlative in nature. DG-specific deletion of the NT-3 gene in adult mice should provide further insights into the relationship between neurogenesis, dentate plasticity, and memory.

While we interpret our results as indicating that neurogenesis plays an important role in dentate LTP, an alternative is that NT-3 facilitates LPP-LTP directly. The effect of NT-3 on hippocampal plasticity has been examined by a number of groups. NT- $3^{+/-}$mice exhibit essentially normal short- and longterm plasticity at the dentate synapses (Asztely et al. 2000; Olofsdotter et al. 2000). The only deficit observed was a reduction in PPF at the LPP synapses (Kokaia et al. 1998; Asztely et al. 2000). An important observation is that acute application of recombinant NT-3 or anti-NT-3 antibodies had no effect on LTP at the CA1 synapses (Figurov et al. 1996; Chen et al. 1999). These results suggest that NT-3 does not modulate synaptic transmission or plasticity directly. Although we cannot rule out a developmental effect of NT-3 on NPCs, since the NT-3 gene is deleted during development, the fact that the DG volume and the total number of granule neuron were not changed suggests that NT-3 is not essential for embryonic neurogenesis or the survival of the DG granule neurons during development.

Assuming adult neurogenesis does regulate dentate LTP, how do newly generated neurons contribute to hippocampusdependent memory? An attractive hypothesis is that new neurons have special properties that allow them to integrate into the existing neural network, leading to an alteration of synaptic plasticity. It has been shown that young neurons form immature synapses at MPP (Wang et al. 2000; Snyder et al. 2001). These synapses exhibit lower threshold for LTP induction, but the magnitude of LTP is smaller when stronger stimulation is used (Snyder et al. 2001; Schmidt-Hieber et al. 2004). Newly generated neurons form new synapses, which are integrated into the existing neural network (Kempermann 2002). Our field-recording experiments showed that LTP in the LPP, but not MPP, was selectively impaired in the NT-3 mutant mice. Why alteration of NPC differentiation affects only LPP but not MPP synapses is not known. An important part of the neuronal differentiation program is to grow elaborate dendritic trees. We speculate that the newly generated neurons in the mutant mice may grow limited dendritic trees that fail to appropriately contact the LPP. In addition, the synaptic connections made by the lateral entorhinal afferents may also be weak. It is conceivable that impairments in 
A

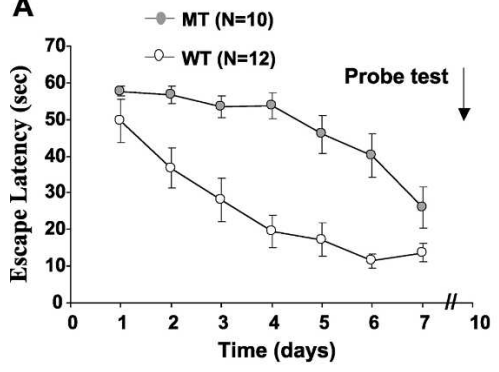

C WT

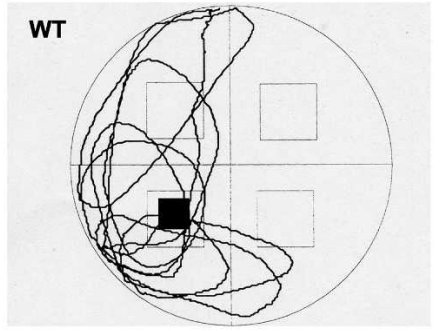

D

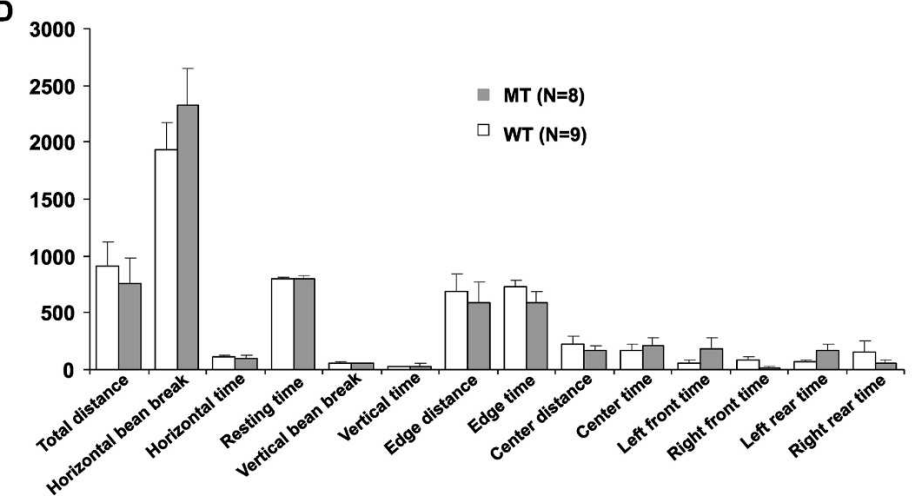

B

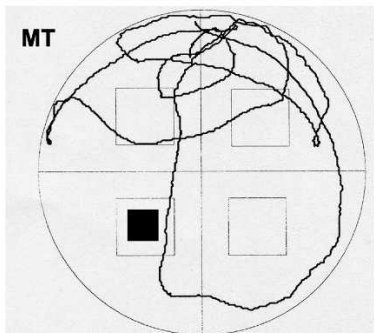

MT $(\mathrm{N}=8)$

$\square$ WT (N=9)

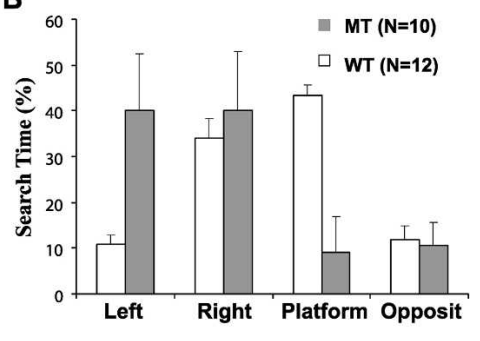

Figure 7. Deficits in spatial learning and memory in NT-3 mutant mice. $(A)$ Deficits in acquisition. The animals were trained twice a day for $7 \mathrm{~d}$ to find the hidden platform. The latency to find the platform is plotted against the training days. The wild-type mice rapidly learned the location of the submerged platform, whereas the mutant mice showed a much slower learning curve (ANOVA $P<0.05)$. (B) Deficits in spatial memory. The probe test conducted at the end of training period. The platform was removed and the animals were allowed to swim freely in the pool for $60 \mathrm{sec}$. The percentage of time the animals spent in each of the four quadrants was measured. The mutant mice spent less time in the platform quadrant than wild-type mice (ANOVA followed by post hoc test, $P<0.002$ ). (C) Representative swim paths illustrate the impairment of spatial cognition during the probe trial in the mutant mice. $(D)$ Open field activity. Locomotor activities were measured every 10 $\mathrm{msec}$ for $10 \mathrm{~min}$. Unit of measurements: time, sec; distance, $\mathrm{cm}$; beam break, number of times. same genetic background) mice were used for experiments. For some experiments, NT-3 $3^{2 l o x / 2 l o x}$, Nes-cre ${ }^{O / O}$ (floxed, in the same genetic background) mice were used as further control. Only male animals were used for experiments. Genotyping, Southern and Northern blotting, and X-gal staining were performed as described (Bates et al. 2002). In all experiments, male, 2-4-mo-old mice were used.

\section{BrdU labeling}

BrdU (Sigma) was dissolved in 0.9\% $\mathrm{NaCl}$ and sterile filtered through $22-\mu \mathrm{m}$ filters. The mice received a single dose of BrdU at $100 \mu \mathrm{g} / \mathrm{gm}$ of body weight from a concentration of $10 \mathrm{mg} / \mathrm{mL}$, one intraperitoneal injection per day for 10 consecutive or for $1 \mathrm{~d}$. Three hours or 2 wk after the last injection of BrdU, the mice were perfused transcardially with $4 \%$ paraformaldehyde in $0.1 \mathrm{M}$ phosphate buffer. The brains were post-fixed overnight, followed by transferring to 30\% sucrose solution. The brain was mounted on a pedestal using Tissue-Tek O.C.T. compound and cut at $40-\mu \mathrm{m}$ sections using a cryostat. The sections were stored at $-80^{\circ} \mathrm{C}$ until use. The 3 -h time point was selected because it is sufficient for BrdU uptake but not for completion of mitosis or migration.

\section{Immunohistochemisry}

All staining was done on free-floating $40-\mu \mathrm{m}$ sections that were derived from brains of BrdU-injected animals. To count the number of BrdU-positive cells, BrdU staining was performed using the ZYMED BrdU staining protocol (Zymed Laboratories Inc.) as described previously (Zhou et al. 2003). Antibodies used for immunofluorescent triple labeling of BrdU, NeuN, and GFAP, were rat antiBrdU (Accurate, Harlan Sera-Lab), 1:100; mouse anti-NeuN (Chemicon), 1:200; and rabbit anti-GFAP (Chemicon), 1:200, respectively. The fluorescent secondary antibodies used were anti-rat Alexa Fluor 488, anti-mouse Alexa Fluor 568, and anti-rabbit Alexa Fluor 647 (Molecular Probe), 1:250. the formation of new synapses contribute to the deficits in field LPP-LTP. Further experiments are necessary to test these ideas.

\section{Materials and Methods}

\section{NT-3 conditional knockout mice}

An NT-3 loxP line was crossed with a transgenic line, in which Cre gene expression was under the control of the Nestin promoter, as previously described (Bates et al. 2002). The following nomenclature was used in the present study. Wild-type, $\mathrm{NT}-3^{+}=+$; Floxed, NT- $3^{210 x}=$ f; Recombined, NT- $3^{110 x}=$ R. Cre positive: + ; Cre

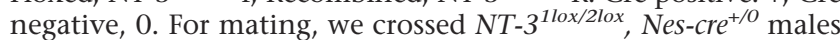

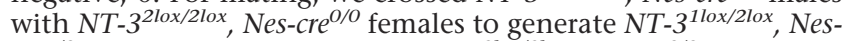
$\mathrm{Cre}^{+/ O}$ offspring. We also crossed NT-3 $3^{2 l o x / 2 l o x}, \mathrm{Nes}-\mathrm{cre} \mathrm{O}^{\mathrm{O} / O}$ males with $N T-3^{2 l o x / 2 l o x}$, Nes-cre $e^{O / O}$ females to generate more NT- $3^{\text {2lox/2lox }}$, Nes$\mathrm{cre}^{O / O}$ offspring. A third type of mating used animals of purely wild types, with the same genetic background as the first two. In general, NT-3 $3^{1 l o x / 2 l o x}, \mathrm{Nes}-\mathrm{Cre}^{+/ 0}$ (MT) and wild-type (WT, in the

\section{Cell counting}

Images were acquired using an Olympus IX 70 microscope equipped with a video camera and the IPlab software (Scanalytics). A 40-um 1-in-6 series of section from mouse was used to quantify the area of hippocampus and the number of positive cells using stereological methods combined with appropriate correction procedures (Gundersen et al. 1988; Coggeshall and Lekan 1996; Guillery and Herrup 1997; Kempermann et al. 1998). The granule cell areas of each section were carefully traced in granule cell layer (GCL), hilus, dentate gyrus, and whole hippocampus. The total areas multiplied the sampled distance to determine the reference volume. For cell counting, histological staining was performed on sections using hematoxylin and eosin (H\&E) staining method. The total granule cell number was estimated by the mean positive cell number multiplied by the reference volume.

Triple-labeled fluorescence images were acquired using BioRad MRC 1024 confocal microscopy and Lasersharp 2000 software (Bio-Rad Laboratories). In total, $100 \sim 200$ BrdU-positive cells per animals were analyzed for coexpression of BrdU 
and NeuN for neuronal phenotype and GFAP for glial phenotype.

\section{Electrophysiological recording}

Transverse hippocampal slices were prepared from 2-mo-old animals, maintained in an interface chamber for both recovery $(>2$ h) and recording, as described previously (Bramham and Sarvey 1996; Pozzo-Miller et al. 1999). Field EPSPs were evoked in CA1 stratum radiatum by stimulating Schaffer collaterals in CA1 region, or in molecular layer by stimulating perforant pathways in DG with Teflon-insulated monopolar electrodes. A brief, highfrequency stimulation (HFS, $100 \mathrm{~Hz}, 20$ pulses) was used to study docked vesicles, and a prolonged, low-frequency stimulation (LFS, $14 \mathrm{~Hz}, 280$ pulses) to study reserved pool vesicles. Tetanus used to induce LTP: CA1 synapses, $100 \mathrm{~Hz}, 1 \mathrm{sec}$, two times with a 20-sec interval; DG synapses, $100 \mathrm{~Hz}, 0.5 \mathrm{sec}$, four times, with a 30-sec interval. Two points are worth mentioning with regard to LTP in the dentate. First, unlike recordings obtained from the submerged chamber (Snyder et al. 2005), the magnitude of LTP from either lateral (LPP) or medial (MPP) perforant pathway in the interface chamber was much bigger. We adjusted the positions of stimulating and recording electrodes to record fEPSPs for MPP or LPP and intensity of tetanus to induce DG LTP, as described previously (Dahl and Sarvey 1989). Second, unlike that in the submerged chamber, the LTP recorded from LPP in the interface chamber is not sensitive to inhibition of GABAergic transmission (see Fig. 5C).

\section{Behavior tests}

1. Morris water maze. A circular pool (diameter: $0.9 \mathrm{~m}$ ) filled with cloudy water was placed in a quiet room with easily identifiable objects on the wall. A circular platform $(12 \mathrm{~cm}$ in diameter) was submerged $1.5 \mathrm{~cm}$ below the water surface and placed in a specific location in the pool. Animals were subjected to four trials a session, two sessions a day. A total of $6 \mathrm{~d}$ of training were given. In each of the four trials, animals were placed at four different starting positions equally spaced around the perimeter of the pool in a random order. Animals were allowed to find the platform within $120 \mathrm{sec}$, or else were guided to the platform. At the end of training, each mouse was given a probe trial (60 sec. with no platform). Memory function was evaluated by the amount of time spent on the correct (platform) quadrant, the distance traveled, and the number of times the animal crossed the platform area.

2. Visual cliff test. An open-topped box $\left(60 \times 60 \times 30 \mathrm{~cm}^{3}\right.$, with clear Perspex bottom) was positioned on the edge of a bench such that half of its base was suspended 1 meter above the ground, creating a visual cliff. Mice were placed at the edge of the cliff, and their activity monitored for $5 \mathrm{~min}$ by a video camera. The percentage of time each mouse spent at the edge, bench side, and open (suspended) area, and the direction in which the first step outside of the edge, were measured.

3. Open-field activity. Animals were individually placed in a Digiscan open-field box (RXYZCM, AccuScan Instruments, Inc.) equipped with two rows of infrared beams that automatically detected and quantified their activities every $10 \mathrm{msec}$ for $10 \mathrm{~min}$. This equipment took measurements of total distance traveled, horizontal and vertical beam breaks, horizontal and vertical time spent, resting time, edge and center time, edge and center distance traveled, and time spent in the left-front, left-rear, right-front, and right-rear areas.

\section{Acknowledgments}

We thank Eminy Lee of the Institute of Biomedical Sciences, Academia Sinica, Taiwan, Republic of China, for initial water maze tests of the mutant mice. We also thank Hongyuan Yan and Vladmir Senatorov for genotyping and Daniel Abebe for behavior experiments. We acknowledge the thoughtful comments and suggestions of Drs. Newton Woo, Hyun-Soo Je, and Petti Pang. In particular, we thank the late John Sarvey for help and advice on the electrophysiological recording of the dentate gyrus. This re- search was supported by the Intramural Research Programs of NICHD (B.L.), and NIDA grant K08 DA000479 (S.A.).

\section{References}

Abraham, W.C. and Williams, J.M. 2003. Properties and mechanisms of LTP maintenance. Neuroscientist 9: 463-474.

Akbarian, S., Bates, B., Liu, R.J., Skirboll, S.L., Pejchal, T., Coppola, V., Sun, L.D., Fan, G., Kucera, J., Wilson, M.A., et al. 2001.

Neurotrophin-3 modulates noradrenergic neuron function and opiate withdrawal. Mol. Psychiatry 6: 593-604.

Asztely, F., Kokaia, M., Olofsdotter, K., Ortegren, U., and Lindvall, O. 2000. Afferent-specific modulation of short-term synaptic plasticity by neurotrophins in dentate gyrus. Eur. J. Neurosci. 12: 662-669.

Barnabe-Heider, F. and Miller, F.D. 2003. Endogenously produced neurotrophins regulate survival and differentiation of cortical progenitors via distinct signaling pathways. J. Neurosci. 23: 5149-5160.

Bates, B., Rios, M., Trumpp, A., Chen, C., Fan, G., Bishop, J.M., and Jaenisch, R. 1999. Neurotrophin-3 is required for proper cerebellar development. Nat. Neurosci. 2: 115-117.

Bates, B., Hirt, L., Thomas, S.S., Akbarian, S., Le, D., Amin-Hanjani, S., Whalen, M., Jaenisch, R., and Moskowitz, M.A. 2002.

Neurotrophin-3 promotes cell death induced in cerebral ischemia, oxygen-glucose deprivation, and oxidative stress: Possible involvement of oxygen free radicals. Neurobiol. Dis. 9: 24-37.

Bramham, C.R. and Sarvey, J.M. 1996. Endogenous activation of $\mu$ and $\delta-1$ opioid receptors is required for long-term potentiation induction in the lateral perforant path: Dependence on GABAergic inhibition. J. Neurosci. 16: 8123-8131.

Bramham, C.R., Southard, T., Sarvey, J., Herkenham, M., and Brady, L.S. 1996. Unilateral LTP triggers bilateral increases in hippocampal neurotrophin and trk receptor mRNA expression in behaving rats: Evidence for interhemispheric communication. J. Comp. Neurol. 368: 371-382.

Cabin, D.E., Shimazu, K., Murphy, D., Cole, N.B., Gottschalk, W., McIlwain, K.L., Orrison, B., Chen, A., Ellis, C.E., Paylor, R., et al. 2002. Synaptic vesicle depletion correlates with attenuated synaptic responses to prolonged repetitive stimulation in mice lacking $\alpha$-synuclein. J. Neurosci. 22: 8797-8807.

Chen, G., Kolbeck, R., Barde, Y.A., Bonhoeffer, T., and Kossel, A. 1999. Relative contribution of endogenous neurotrophins in hippocampal long-term potentiation. J. Neurosci. 19: 7983-7990.

Coggeshall, R.E. and Lekan, H.A. 1996. Methods for determining numbers of cells and synapses: A case for more uniform standards of review. J. Comp. Neurol. 364: 6-15.

Cotman, C.W. and Berchtold, N.C. 2002. Exercise: A behavioral intervention to enhance brain health and plasticity. Trends Neurosci. 25: $295-301$.

Dahl, D. and Sarvey, J.M. 1989. Norepinephrine induces pathway-specific long-lasting potentiation and depression in the hippocampal dentate gyrus. Proc. Natl. Acad. Sci. 86: 4776-4780.

Figurov, A., Pozzo-Miller, L., Olafsson, P., Wang, T., and Lu, B. 1996. Regulation of synaptic responses to high-frequency stimulation and LTP by neurotrophins in the hippocampus. Nature 381: 706-709.

Friedman, W.J., Ernfors, P., and Persson, H. 1991. Transient and persistent expression of NT-3/HDNF mRNA in the rat brain during postnatal development. J. Neurosci. 11: 1577-1584.

Fuchs, E. and Gould, E. 2000. Mini-review: In vivo neurogenesis in the adult brain: Regulation and functional implications. Eur. J. Neurosci. 12: 2211-2214.

Gage, F.H. 2000. Mammalian neural stem cells. Science 287: 1433-1438.

Gao, X.B. and van den Pol, A.N. 1999. Neurotrophin-3 potentiates excitatory GABAergic synaptic transmission in cultured developing hypothalamic neurones of the rat. J. Physiol. 518: 81-95.

Ghosh, A. and Greenberg, M.E. 1995. Distinct roles for bFGF and NT-3 in the regulation of cortical neurogenesis. Neuron 15: 89-103.

Gould, E. and Gross, C.G. 2002. Neurogenesis in adult mammals: Some progress and problems. J. Neurosci. 22: 619-623.

Gould, E., Beylin, A., Tanapat, P., Reeves, A., and Shors, T.J. 1999a. Learning enhances adult neurogenesis in the hippocampal formation. Nat. Neurosci. 2: 260-265.

Gould, E., Tanapat, P., Hastings, N.B., and Shors, T.J. 1999b. Neurogenesis in adulthood: A possible role in learning. Trends Cogn. Sci. 3: 186-192.

Guillery, R.W. and Herrup, K. 1997. Quantification without pontification: Choosing a method for counting objects in sectioned tissues. J. Comp. Neurol. 386: 2-7.

Gundersen, H.J., Bagger, P., Bendtsen, T.F., Evans, S.M., Korbo, L., Marcussen, N., Moller, A., Nielsen, K., Nyengaard, J.R., Pakkenberg, B., et al. 1988. The new stereological tools: Disector, fractionator, nucleator and point sampled intercepts and their use in pathological 
research and diagnosis. APMIS 96: 857-881.

Hanse, E. and Gustafsson, B. 1992. Long-term potentiation and field EPSPs in the lateral and medial perforant paths in the dentate gyrus in vitro: A comparison. Eur. J. Neurosci. 4: 1191-1201.

Kempermann, G. 2002. Why new neurons? Possible functions for adult hippocampal neurogenesis. J. Neurosci. 22: 635-638.

Kempermann, G., Kuhn, H.G., and Gage, F.H. 1997. More hippocampal neurons in adult mice living in an enriched environment. Nature 386: 493-495.

. 1998. Experience-induced neurogenesis in the senescent dentate gyrus. J. Neurosci. 18: 3206-3212.

Kempermann, G., Jessberger, S., Steiner, B., and Kronenberg, G. 2004a. Milestones of neuronal development in the adult hippocampus. Trends Neurosci. 27: 447-452.

Kempermann, G., Wiskott, L., and Gage, F.H. 2004b. Functional significance of adult neurogenesis. Curr. Opin. Neurobiol. 14: $186-191$.

Kim, H.G., Wang, T., Olafsson, P., and Lu, B. 1994. Neurotrophin 3 potentiates neuronal activity and inhibits $\gamma$-aminobutyrateric synaptic transmission in cortical neurons. Proc. Natl. Acad. Sci. 91: $12341-12345$

Kokaia, M., Asztely, F., Olofsdotter, K., Sindreu, C.B., Kullmann, D.M., and Lindvall, O. 1998. Endogenous neurotrophin-3 regulates short-term plasticity at lateral perforant path-granule cell synapses. $J$. Neurosci. 18: 8730-8739.

Lauterborn, J.C., Isackson, P.J., and Gall, C.M. 1994. Cellular localization of NGF and NT-3 mRNAs in postnatal rat forebrain. Mol. Cell. Neurosci. 5: 46-62.

Lee, J., Duan, W., Long, J.M., Ingram, D.K., and Mattson, M.P. 2000. Dietary restriction increases the number of newly generated neural cells, and induces BDNF expression, in the dentate gyrus of rats. $J$. Mol. Neurosci. 15: 99-108.

Lindvall, O., Ernfors, P., Bengzon, J., Kokaia, Z., Smith, M.L., Siesjo, B.K., and Persson, H. 1992. Differential regulation of mRNAs for nerve growth factor, brain-derived neurotrophic factor, and neurotrophin 3 in the adult rat brain following cerebral ischemia and hypoglycemic coma. Proc. Natl. Acad. Sci. 89: 648-662.

Lu, B. and Chang, J. 2005. Regulation of neurogenesis by neurotrophins: Implications in hippocampus-dependent memory. Neuron Glia Biol. 1: $377-384$.

Ma, L., Reis, G., Parada, L.F., and Schuman, E.M. 1999. Neuronal NT-3 is not required for synaptic transmission or long-term potentiation in area CA1 of the adult rat hippocampus. Learn. Mem. 6: 267-275.

Ma, L., Harada, T., Harada, C., Romero, M., Hebert, J.M., McConnell, S.K., and Parada, L.F. 2002. Neurotrophin-3 is required for appropriate establishment of thalamocortical connections. Neuron 36: 623-634.

Madsen, T.M., Kristjansen, P.E., Bolwig, T.G., and Wortwein, G. 2003. Arrested neuronal proliferation and impaired hippocampal function following fractionated brain irradiation in the adult rat. Neuroscience 119: 635-642.

Maisonpierre, P.C., Belluscio, L., Friedman, B., Alderson, R.F., Wiegand, S.J., Furth, M.E., Lindsay, R.M., and Yancopoulos, G.D. 1990. NT-3, BDNF, and NGF in the developing rat nervous system: Parallel as well as reciprocal patterns of expression. Neuron 5: 501-509.

Martinez, A., Alcantara, S., Borrell, V., Del Rio, J.A., Blasi, J., Otal, R., Campos, N., Boronat, A., Barbacid, M., Silos-Santiago, I., et al. 1998. TrkB and TrkC signaling are required for maturation and synaptogenesis of hippocampal connections. J. Neurosci. 18: $7336-7350$.

Monje, M.L., Mizumatsu, S., Fike, J.R., and Palmer, T.D. 2002. Irradiation induces neural precursor-cell dysfunction. Nat. Med. 8: $955-962$.

Nilsson, M., Perfilieva, E., Johansson, U., Orwar, O., and Eriksson, P.S. 1999. Enriched environment increases neurogenesis in the adult rat dentate gyrus and improves spatial memory. J. Neurobiol. 39: $569-578$.

Olofsdotter, K., Lindvall, O., and Asztely, F. 2000. Increased synaptic inhibition in dentate gyrus of mice with reduced levels of endogenous brain-derived neurotrophic factor. Neuroscience 101: $531-539$.

Pozzo-Miller, L., Gottschalk, W.A., Zhang, L., McDermott, K., Du, J., Gopalakrishnan, R., Oho, C., Shen, Z., and Lu, B. 1999. Impairments in high frequency transmission, synaptic vesicle docking and synaptic protein distribution in the hippocampus of BDNF knockout mice. J. Neurosci. 19: 4972-4983.

Richter-Levin, G., Canevari, L., and Bliss, T.V. 1995. Long-term potentiation and glutamate release in the dentate gyrus: Links to spatial learning. Behav. Brain Res. 66: 37-40.

Rola, R., Raber, J., Rizk, A., Otsuka, S., VandenBerg, S.R., Morhardt, D.R., and Fike, J.R. 2004. Radiation-induced impairment of hippocampal neurogenesis is associated with cognitive deficits in young mice. Exp. Neurol. 188: 316-330.

Schmidt-Hieber, C., Jonas, P., and Bischofberger, J. 2004. Enhanced synaptic plasticity in newly generated granule cells of the adult hippocampus. Nature 429: 184-187.

Shors, T.J., Miesegaes, G., Beylin, A., Zhao, M., Rydel, T., and Gould, E. 2001. Neurogenesis in the adult is involved in the formation of trace memories. Nature 410: 372-376.

Snyder, J.S., Kee, N., and Wojtowicz, J.M. 2001. Effects of adult neurogenesis on synaptic plasticity in the rat dentate gyrus. $J$. Neurophysiol. 85: 2423-2431.

Snyder, J.S., Hong, N.S., McDonald, R.J., and Wojtowicz, J.M. 2005. A role for adult neurogenesis in spatial long-term memory. Neuroscience 130: 843-852.

Song, H.J., Stevens, C.F., and Gage, F.H. 2002. Neural stem cells from adult hippocampus develop essential properties of functional CNS neurons. Nat. Neurosci. 5: 438-445.

Soriano, P. 1999. Generalized lacZ expression with the ROSA26 Cre reporter strain. Nat. Genet. 21: 70-71.

van Praag, H., Christie, B.R., Sejnowski, T.J., and Gage, F.H. 1999a. Running enhances neurogenesis, learning, and long-term potentiation in mice. Proc. Natl. Acad. Sci. 96: 13427-13431.

van Praag, H., Kempermann, G., and Gage, F.H. 1999b. Running increases cell proliferation and neurogenesis in the adult mouse dentate gyrus. Nat. Neurosci. 2: 266-270.

van Praag, H., Schinder, A.F., Christie, B.R., Toni, N., Palmer, T.D., and Gage, F.H. 2002. Functional neurogenesis in the adult hippocampus. Nature 415: 1030-1034.

Vicario-Abejon, C., Johe, K.K., Hazel, T.G., Collazo, D., and McKay, R.D. 1995. Functions of basic fibroblast growth factor and neurotrophins in the differentiation of hippocampal neurons. Neuron 15: 105-114.

Vicario-Abejon, C., Collin, C., McKay, R.D., and Segal, M. 1998. Neurotrophins induce formation of functional excitatory and inhibitory synapses between cultured hippocampal neurons. $J$. Neurosci. 18: 7256-7271.

Vicario-Abejon, C., Collin, C., Tsoulfas, P., and McKay, R.D. 2000. Hippocampal stem cells differentiate into excitatory and inhibitory neurons. Eur. J. Neurosci. 12: 677-688.

Wang, S., Scott, B.W., and Wojtowicz, J.M. 2000. Heterogenous properties of dentate granule neurons in the adult rat. J. Neurobiol. 42: $248-257$.

Zhao, X., Ueba, T., Christie, B.R., Barkho, B., McConnell, M.J., Nakashima, K., Lein, E.S., Eadie, B.D., Willhoite, A.R., Muotri, A.R., et al. 2003. Mice lacking methyl-CpG binding protein 1 have deficits in adult neurogenesis and hippocampal function. Proc. Natl. Acad. Sci. 100: 6777-6782.

Zhou, Y.X., Zhao, M., Li, D., Shimazu, K., Sakata, K., Deng, C.X., and Lu, B. 2003. Cerebellar deficits and hyperactivity in mice lacking Smad4. J. Biol. Chem. 278: 42313-42320.

Zucker, R.S. 1989. Short-term synaptic plasticity. Annu. Rev. Neurosci. 12: $13-31$.

Received September 3, 2005; accepted in revised form February 9, 2006. 


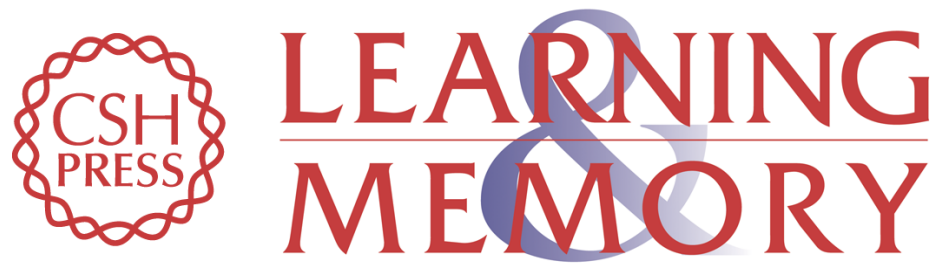

\section{NT-3 facilitates hippocampal plasticity and learning and memory by regulating neurogenesis}

Kazuhiro Shimazu, Mingrui Zhao, Kazuko Sakata, et al.

Learn. Mem. 2006, 13:

Access the most recent version at doi:10.1101/lm.76006

References This article cites 63 articles, 20 of which can be accessed free at:

http://learnmem.cshlp.org/content/13/3/307.full.html\#ref-list-1

License

Email Alerting Receive free email alerts when new articles cite this article - sign up in the box at the Service top right corner of the article or click here. 